\title{
Digital Divide of Russia's Regions
}

\author{
Aibika Beksultanova ${ }^{1, *}$, Liza Gaisumova ${ }^{2}$, and Movsar Eniev ${ }^{2}$ \\ ${ }^{1}$ Chechen State University, 364024 Grozny, Russia \\ ${ }^{2}$ Chechen State Pedagogical University, 364037 Grozny, Russia
}

\begin{abstract}
Digital technologies in all spheres of life are becoming an increasingly necessary requirement of the current era, an imperative for states that want to ensure themselves a foothold in an ever-changing world. It is no coincidence that the Digital Economy has become one of Russia's key programs to shape the country's future. This paper analyses the digital divide between cities by comparing settlements of different sizes, economic structure, income levels and histories. Such comparisons provide a voluminous analysis of the digitalisation of the country as a whole, assisting in strategic decision-making in both government and business. The analysis leads to conclusions and proposes key directions for a possible program of action for the regions.
\end{abstract}

\section{Introduction}

Unfolding of the digital revolution on a global scale is increasingly plunging us into a new reality [1]. The variety of technical and technological innovations changing our lives has increased manifold over the last decade in a wide range of human activities [2]. Digitalisation is one of the main tracks of economic development. However, the notion does not only apply to economic categories, as access to digital technology changes everything: it makes agriculture and industry more efficient, it improves the quality of life of citizens, it facilitates access to information, access to customers for small and mediumsized businesses, including media, it contributes to a complete change in the relationship between the state and citizens and even provides new forms of democracy, such as evoting.

Today, digitalisation appears as a qualitatively different level of automation, oriented towards an intelligent control system, which involves the use of modern methods of big data processing. Its main task is to integrate technology, machines and personnel into a common environment that provides the high efficient production required for the technological breakthrough of the Russian Federation [3].

The ability of a region to exploit all the opportunities of the digital economy is a major advantage in competing for investors, and regions, having created the necessary environment, of course compete for investors. It is a matter of registering a company quickly, registering a land plot, obtaining a building permit, obtaining data on all communications, historical monuments and other conditions. [4].

* Corresponding author: adamovaaybika@mail.ru 
The digitalisation of all spheres of society is becoming an increasingly important factor in the socio-economic development of states and regions. This digital unfolding creates new opportunities for accelerated growth on the one hand, but on the other, it also raises risks, such as the "digital divide", the widening gap between regions or countries that are insufficiently resourced for effective digitalisation. The "digital divide" between states is becoming an increasingly significant global problem, but it can also be traced within each state, between socio-demographic groups or regions.

\section{Methods and types of the Earth's remote sensing}

Based on research by experts of the Moscow School of Management SKOLKOVO, describing the digital life of Russian regions, the main directions of development in the digitalisation of economies have been characterised. The methods of the research performed contain statistical and analytical methods and are supported by graphical methods of data illustration.

\section{Analysis of the main ERS data sources for the DEM development}

In an age when digitalisation is becoming a major driver of socio-economic growth at the enterprise, regional and national levels, the digital divide - the gap in technological capabilities - is becoming an increasingly important issue. This divide can be traceable between regions, within each country or within socio-demographic groups. At any given time, some degree of digital divide is objectively present, but beyond a certain point, the digital divide becomes politically and socially unacceptable: it is unacceptable for members of information-poor social groups or regions to find themselves in "another universe" in terms of their social and economic opportunities. The answers to two questions are very important: whether the extent of the digital divide decreases or increases over time in the "natural" evolution of the situation, and whether the lagging subjects are likely to overcome the digital divide on their own.

Almost the whole world has moved from "primary" digital technology - which is concerned with building the necessary infrastructure to access the Internet - to "secondary" technology, i.e. creating as many separate digitalisation solutions as possible that are integrated into a single system.

Let us study the development of the digital economy in Russia and the Russian regions.

The sample of cities in this study was dramatically expanded to include all the capitals of the Russian regions, as well as major "non-capital" regional centers (Volzhsky, Naberezhnye Chelny, Nizhny Tagil, Novokuznetsk, Sochi, Surgut, Togliatti, Cherepovets), 91 cities in total. This expanded field of analysis made it possible to compare cities that are very different in scale, economic structure, income level and history. Such comparisons enable a multidimensional analysis of Russian digitalisation as a whole, facilitating strategic decision-making in both business and public administration.

Among Russian regions, the second level of the digital divide is very significant: the value of the final Digital Life Index of the leading cities (Yekaterinburg and Krasnodar) is almost 5 times greater than that of the last city (Magas-Nazran, as a single agglomeration). The Index trajectory highlights three categories: leaders - the top 19 cities (with two "super-leaders", Yekaterinburg and Krasnodar, which are far away from all others), "average" and laggards, highlighted by 9 cities (see figure 1). Towards the end of the distribution, the drop in the index increases sharply, indicating that there are systemic problems in digitalisation in the "laggard" group. 


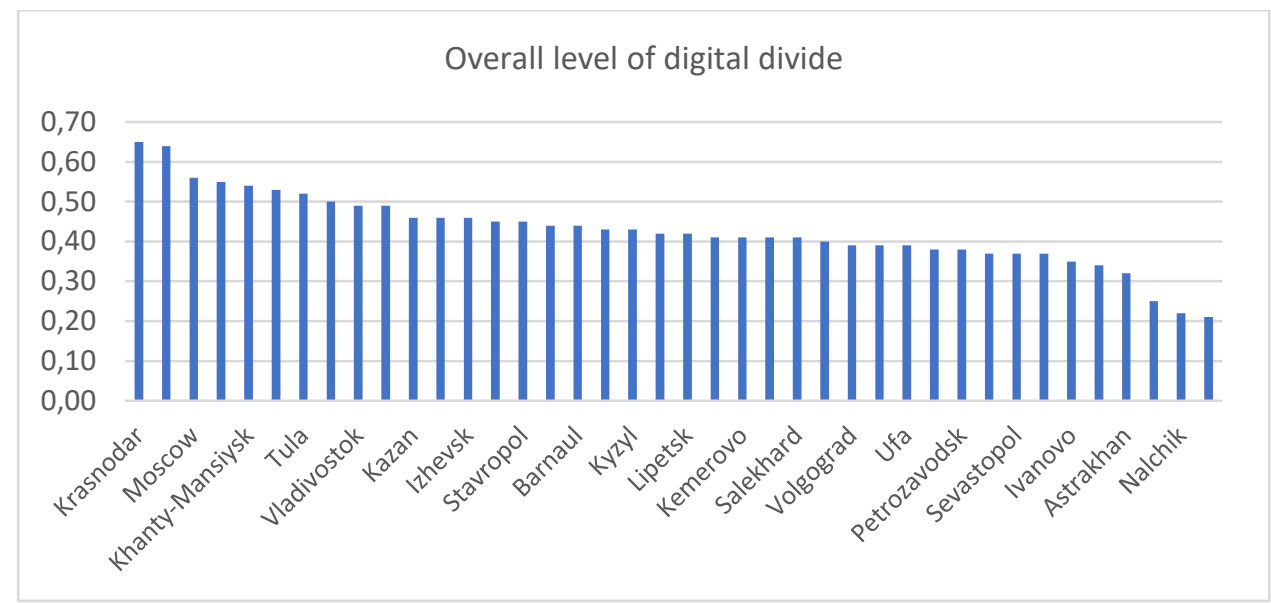

Fig. 1. Distribution of the total value of the Digital Life Index.

However, separate values of the digital supply index and digital demand index show significantly different dynamics. The distribution of supply is considerably more even, with the difference between the closing city and the leading city being reduced by up to a factor of three. Accordingly, the digital demand divide contributes significantly more to the overall digital divide, which is fully consistent with the judgement of the "second-tier" divide, which is determined by differences in population competencies and digital skills.

Despite popular judgement, the relationship between a city's digital saturation and its size is not entirely linear [5]: the trend that, with decreasing city size, digitalisation weakens is not applicable to the smaller cities in the sample of less than 100,000 inhabitants; they show higher index levels than cities of 100,000 to 200,000 inhabitants (see figure 2).

Digital divide according to urban population

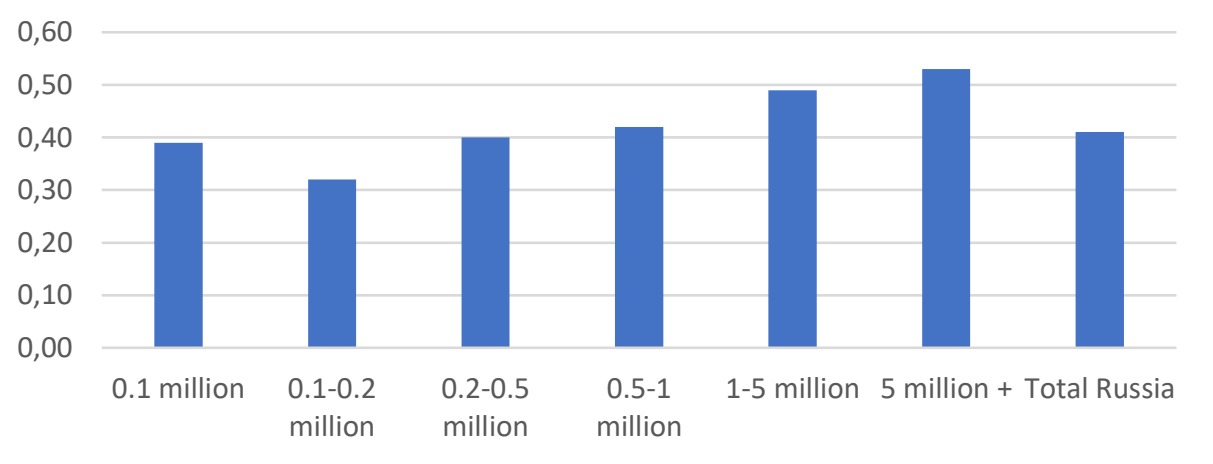

Fig. 2. Digital divide according to urban population

This can be explained to some extent by the fact that in many cases small capitals are located in resource extraction regions with high gross regional product (Salekhard, KhantyMansiysk, Anadyr, Naryan-Mar, Magadan), but fairly poor Birobidzhan and Gorno-Altaisk also perform reasonably well. It seems that the compactness of society and the urban environment are factors that accelerate digital unfolding, particularly the demand for digital technology. Smaller cities outperform even cities of 500,000 to 1 million inhabitants, second only to cities with millions of inhabitants. At the same time, digital supply decreases 
smoothly with city size, but here two Russian megacities (St. Petersburg and Moscow) no longer differ from other cities with millions of inhabitants (see figure 3 ).

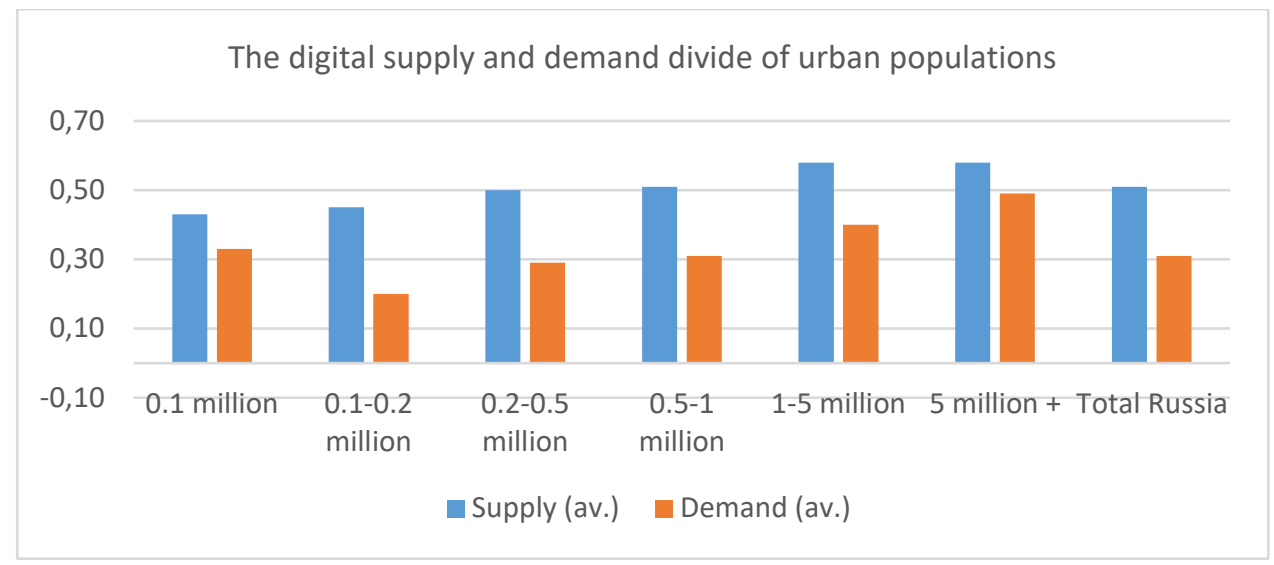

Fig. 3. The digital supply and demand divide of urban populations

The leaders at the federal district level are the Central and Ural districts. The Southern Federal District finds itself in the middle of the ranking despite the leadership of Krasnodar among cities, and the North Caucasian Federal District closes it with a large gap (see figure 4). Approximately the same picture can be seen in the 2014 and 2015 surveys, where Rostov-on-Don and Volgograd were the laggards among the cities with millions of inhabitants. Interestingly, the picture changes when supply and demand are analysed separately: Central, Ural and North-West are the leaders in demand, while South, Siberia and Urals lead in supply. The difference in the level of demand is much more pronounced than in the level of supply, as well as with respect to the distribution by city size [6].

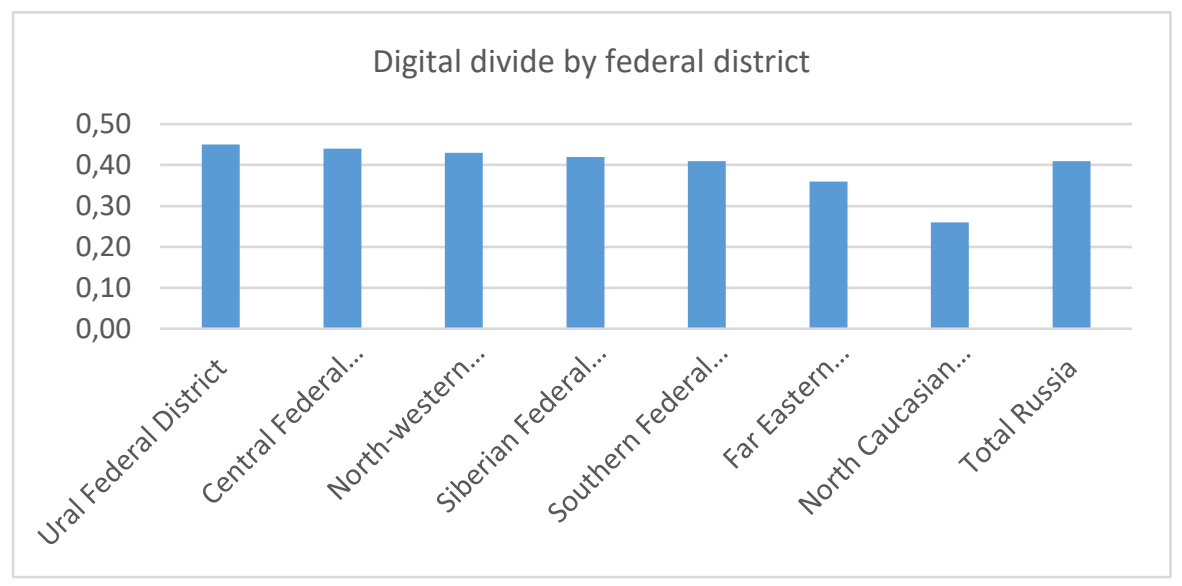

Fig. 4. Digital divide by federal district

The analysis leads to the conclusion that digital unfolding in the regions and cities is uneven and the pace is not high enough, which is due to the different resource, transport and methodological support of the various constituent entities of Russia.

Lagging regions should be guided by the experience of leading regions. Bridging the digital divide can be achieved through targeted strategic action. Any region can and should strive to maximise digitalisation to produce meaningful effects: 
- Accelerate socio-economic development, improve the quality of economic growth (correcting structural imbalances in resource-rich regions);

- Equalise access to socio-economic resources, reduce inequality, ensure inclusiveness of opportunities;

- Create a modern quality of life, personal fulfilment of citizens;

- Develop the region's "soft power", its competitiveness both inside and outside the country.

Key areas of action for business leaders, administration and opinion leaders in each region should be highlighted:

1. Creating competencies and skills in the effective application of digital platforms and systems, and developing digital demand. As has been said, it is the difference in demand that largely illustrates the digital divide between regions.

2. Development of digital competences undoubtedly requires an overall increase in the quality of human capital in the region, and the creation of an artful, fruitful innovative environment in the region. It is the components of human capital that, according to the results of statistical analysis, have become the most significant factors that determine the level of digital life in a particular city.

3. Creation of a digital supply should not be overlooked. Nevertheless, experiments that offer different business models to consumers rather than one-off super-projects are more effective here. According to foreign studies, one of the main factors in the quality of digitalisation is the competitiveness of the products offered in the market and the concreteness of the market itself [7].

\section{Conclusions}

The digital sector in the world is developing at a tremendous speed. Every year, the number of users of the latest digital advances increases. The implementation of digital technologies is seen by the world's leading countries as one of the main factors enhancing competitive advantages and innovative development. It should be noted that Russian regions have made some progress in the development of digitalisation at the enterprise, household and digital government level in recent years.

However, there are unresolved issues of bureaucracy in the introduction of digital technologies in the regions, uneven territorial development and the lack of a clearly defined legislative framework in this area.

In order to develop the regional digital economy, it is necessary to create an all-Russian rating of digital development of the regions and share best practices, organize training of regional managers in digital technologies, coordinate digitalization processes in the regions at the federal level, and align the situations in the regions. The formation of new structures for the development of digital systems, vertical and horizontal cooperation between sectors of the economy, the interaction of the state, research institutes based on private enterprises and universities contributes to the development of the digital economy in the regions [8].

Digitalisation has become an important factor in the overall perceived quality of the urban environment. It has become one of the main tools for regions and cities to compete on the national and global human capital markets, to develop, attract and retain ambitious, successful, innovative people, those who can give a new impetus to the socio-economic development of the region. Consequently, bridging the digital divide is an important part of a comprehensive response to the challenges faced by every region of Russia. 


\section{Acknowledgements}

The article has been prepared as a part of the public task of the Institute of Mining, Ural Branch of the Russian Academy of Sciences on the topic No.0328-2019-0005.

\section{References}

1. A. Bereznoi, World economy and international relations, 62(9), 5 (2018)

2. E. Sadovaya, World economy and international relations, 62(12), 35 (2018)

3. From automation to digitalisation, or the intelligent transformation of Russian manufacturing, https://www.elec.ru/

4. The digital life of Russian megacities, Moscow School of Management SKOLKOVO (2016)

5. Development of the digital economy in Russia's regions. Potential and prospects, https://forumspb.com/

6. Russia in international rankings, https://www.cnews.ru/

7. Digital Life of Russian Regions 2020, SKOLKOVO Institute for Emerging Market Studies (IEMS), https://ict.moscow/

8. A.V. Minakov, L.O. Evraev, Potential and Prospects of Russia's Digital Economy, 3(63) (2020) 